\title{
Monitoring thermal field, humidity field and energy balance over heterogeneous surfaces in the typical valley-city
}

\author{
LI Guodong ${ }^{1,2}$, "ZHANG Junhua ${ }^{1,2}$, MIRZAEI Parham A. ${ }^{3}$, DING Shengyan ${ }^{1,2}$, \\ DING Yapeng ${ }^{1}$, LIU Man ${ }^{1}$ \\ 1. College of Environment and Planning, Henan University, Kaifeng 475004, Henan, China; \\ 2. Key Laboratory of Geospatial Technology for the Middle and Lower Yellow River Regions (Henan University), \\ Ministry of Education, Kaifeng 475004, Henan, China; \\ 3. Department of Architecture and Built Environment, The University of Nottingham, Nottingham NG7 2RD, UK
}

\begin{abstract}
Land use and land cover (LULC) alteration has changed original energy balance and heat fluxes between land and atmosphere, and thus affects the structure characteristics of temperature and humidity fields over urban heterogeneous surfaces in different spatio-temporal scales. Lanzhou is the most typical river valley city of China, it is chosen as the case study. Typical river valley terrain, rapid urbanization and severe air pollution have caused unique urban climate and urban heat island (UHI) effects in Lanzhou. Firstly, the spatial structure characteristics and dynamic evolution of temperature and humidity fields in autumn are simulated by mobile measurement experiment and GIS spatial analysis method. The results show that temperature and humidity fields have significant dynamic change within a day, and have multiple center and multiple intensity level characteristics. Then, LULC and normalized difference vegetation index (NDVI) are extracted from remote sensing images, the distribution patterns of temperature and humidity fields have close relationships with LULC and NDVI. Moreover, there is a significant positive correlation between impervious surface area and thermal field intensity. A positive correlation between NDVI value and humidity field intensity has been found as well as a negative correlation between NDVI value and thermal field intensity. Finally, heat fluxes and energy balance characteristics between ground and atmosphere are analyzed based on the Bowen-ratio System experiments. This study could provide theoretical support and practical guidance for urban planning, urban eco-environment construction and air pollution prevention of river valley city.
\end{abstract}

Keywords: thermal field; humidity field; energy balance; heat fluxes; LULC; valley-city

Received: 2020-03-09 Accepted: 2020-07-23

Foundation: National Natural Science Foundation of China, No.U1404401, No.41771202; Natural Science Foundation of Henan Province, No.182300410129; Open Fund of Henan Key Laboratory of Integrated Air Pollution Control and Ecological Security, No.20170201

Author: Li Guodong, Associate Professor, specialized in urban climate and land surface processes.

E-mail: liguodonghd@163.com

"Corresponding author: Zhang Junhua, Professor. E-mail: zhangjunhua@henu.edu.cn 


\section{Introduction}

Rapid urbanization dramatically changes the regional LULC, exerting its effects on the local weather, atmospheric boundary layer structure, local circulation (Akbari and Kolokotsa, 2016; Silva et al., 2018) and greatly affect urban temperature and humidity fields (Rizwan et al., 2008; Schatz and Kucharik, 2015) through changing land-atmosphere heat fluxes and energy budget (Li et al., 2011). Urban heat island (UHI) is the most obvious climatic phenomena caused by modern urbanization, it has been investigated in different global regions (Arnds et al., 2017; Qi et al., 2020). Urban temperature and humidity fields are main control factors of physical, chemical, ecological and biological processes on the land surface (Small, 2006), it greatly affects the flow of matter and energy, and produces a series of eco-environmental effects (Grimm et al., 2008; Melaas et al., 2016; Zipper et al., 2016). The research on matter and energy transfer process over the horizontal and homogeneous underlying surface has made substantial progress, international research focus has been shifted to heterogeneous underlying surface, including observation and numerical simulation of atmospheric boundary layer, the research on the interplay between the heterogeneous underlying surface and atmosphere has became an important aspect in the global climate change sciences (Li et al., 2018).

At present, the effects of urban LULC change on global climate change have become a focus in the scientific community (Wang, 2010). One view is that it has been understood that urban LULC alteration affects the rise of temperature on the earth surface (Kalnay and Cai, 2003). Another view suggests that the large-scale global warming has little to do with urbanization (David, 2004). In addition, the contribution rate of the UHI effect on the regional and global warming process is also a controversial issue (Shao et al., 2009). We hold the opinion that it is difficult to accurately estimate the impact of urbanization on individual weather stations and regional average temperature series; at present, there is no method to conduct validation and correction of the heat island effect for every meteorological station; moreover, the level of urban development in various countries is different, these factors have caused difficulties for unified correction of meteorological station data. Therefore, finding correct answers to the above questions heavily depends on research of land surface process. At present, the studies on land surface temperature (LST) by thermal infrared remote sensing are extensive and in-depth (Rajasekar and Weng, 2009; Kourtidis et al., 2015; Shirani-idabadi et al., 2019). However, less effort has been put into the temperature and humidity fields of the near-surface atmosphere layer in urban areas, especially the humidity fields.

Most of current research is focused on the remote sensing inversion of either brightness temperature or LST (Benas et al., 2017), but brightness temperature and LST are significantly different from near surface air temperature (NSAT) due to complex atmospheric conditions and the properties of urban land surfaces (Mirzaei and Haghighat, 2010; Zhang et al., 2010; Ho et al., 2016). The thermodynamic model is usually used to calculate NSAT, it needs LST, NDVI, net radiation and aerodynamic drag coefficient parameters and others as inputs, but most of the physical parameters are difficult to acquire, so the calculated NSAT error is big. Besides, it is difficult to monitor the dynamic variations characteristics within a day by remote sensing inversion method.

Given the above considerations, the aim of this research is to combine both mobile and 
fixed-point measurements, geo-statistical methods, GIS spatial analysis, and the quantitative remote sensing to obtain the structure characteristics of the urban temperature and humidity fields with high spatio-temporal resolution. Moreover, this study intends to depict the complex physical process through which LULC alteration drove the evolution of the temperature and humidity fields and climate effects in the near-surface heterogeneous layer of the urban areas. Lanzhou city, the most typical river valley city of China, was identified as a study case, for its typical river valley terrain, rapid urbanization and severe air pollution have caused unique urban climate and UHI effects. The study could provide theoretical support for air pollution prevention, urban planning, land use and urban eco-environment construction of valley cities.

\section{Study area}

The city of Lanzhou is situated in the contiguous zone of the Loess Plateau, Tibetan Plateau and Inner Mongolia Plateau (Figure 1). It is surrounded by mountains, stretches across the Yellow River basin, the relative height of the river valley basin is approximately $600 \mathrm{~m}$, six-step terraces have been developed in the Yellow River valley basin. Lanzhou has typical temperate semiarid climatic characteristics, annual mean temperature is $9.3^{\circ} \mathrm{C}$, and annual precipitation is $333 \mathrm{~mm}$. Lanzhou is important petrochemistry, metallurgy and machinery industrial bases of China, air pollution is quite serious. Since the 1980s, Lanzhou has experienced a rapid growth in urbanization, with its population increasing from 86 thousand in 1949 to 4.134 million in 2019. As shown in Figure 2, calculated by the proportion of non-agricultural population, Lanzhou's urbanization level jumped from $45.6 \%$ in 1978 to $62.7 \%$ in 2010 , which was well above the national average. The urban built-up area of Lanzhou expanded very sharply in the past half of the century as shown in Figure 3. For instance, its urban built-up area was only $0.16 \mathrm{~km}^{2}$ in Sui and Tang dynasties (581-907 AD), stood at $4.48 \mathrm{~km}^{2}$ in the early days of new China, but rocketed to $330.57 \mathrm{~km}^{2}$ in 2019 , fully reflecting Lanzhou's rapid expansion speed.

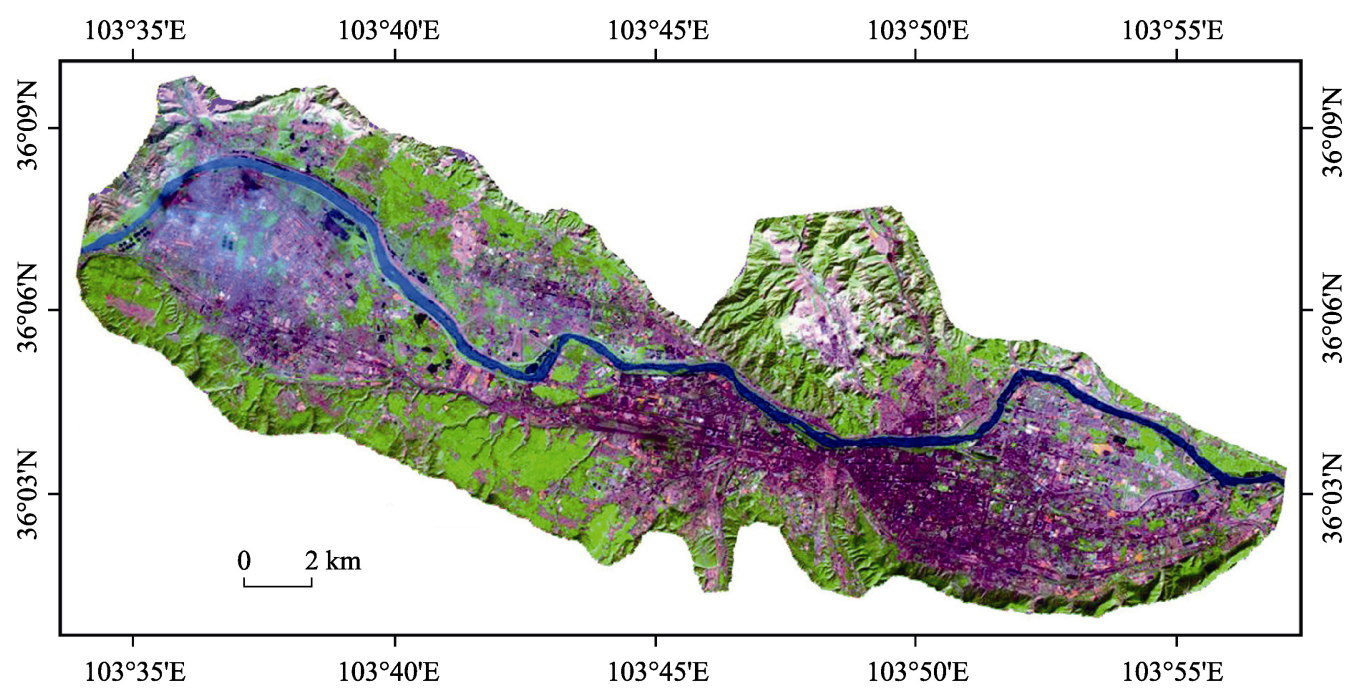

Figure 1 Study area shown in TM false-color image (R band 7, G band 4, B band 3) 


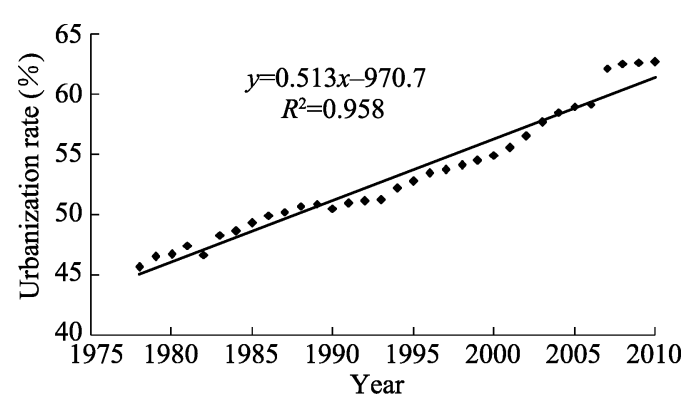

Figure 2 Urbanization level of Lanzhou

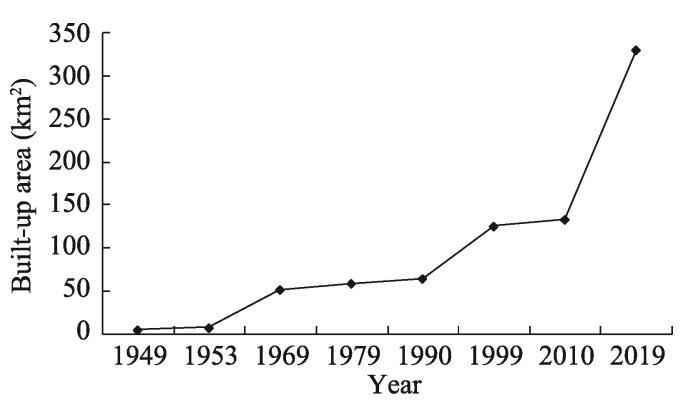

Figure 3 Urban built-up area at different periods in Lanzhou

As a river valley city, Lanzhou has experienced restrictions of natural conditions, and gradually developed into the one with multi-functional divisions and multi-center groups, which deeply influence the urban temperature and humidity fields, and urban climate characteristics are different from other cities located in plains. Besides, air pollution in valley cities are universal across the world, while the diffusion of atmospheric pollutants has a close relationship with heat island circulation and land-atmospheric energy exchange process (Yang et al., 2010). In addition, the special terrain and weather conditions make thermal inversion layer easily formed over the valley city, and frequencies of static winds are high in the atmospheric boundary layer. The combination of human and natural factors makes Lanzhou's climate, temperature and humidity fields, and the related driving mechanism more unique in comparison with the other cities.

\section{Data and methods}

\subsection{Measurement experiments}

\subsubsection{Mobile and fixed-point measurement experiments}

Mobile and fixed-point measurements of multiple meteorological elements were conducted in typical urban area of Lanzhou using vehicles during Jan. 1999, Apr. 1999, Oct. 1999, Jul. 2000, Jul. 2006, Oct. 2006, Jan. 2007, Apr. 2007, Jul. 2016, Oct. 2016, Dec. 2016, and May 2017. Measurement experiments were conducted under clear and calm weather conditions. Figure 4 shows the measurement routes and points. Different urban areas, LULC types, construction density and other factors were synthetically considered in design of measurement routes and points. During the period of measurement, multi-functional meteorological instrument (Kestrel 4000, USA), ventilated psychrometer (DHM2, China), GPS (Magellan 320, USA) and aneroid barometer (DYM3, China) were respectively carried by two cars to simultaneously observe the weather parameters in the east and west routes. The daily measurements were run respectively in the morning, at noon and night; each measurement was approximately continued for 3-4 hours, so daily measurement periods were 7:00-10:00 am, 13:00-16:00 pm, 19:00-22:00 pm, respectively. After arriving at every observation point, the instruments were moved from cars to empty area to avoid disturbance of external factors. At the same time during the mobile measurement, fixed-point measurement was simultaneously conducted with 
multi-functional meteorological instrument, ventilated psychrometer and aneroid barometer in Panxuan Road Campus of Lanzhou University in urban center, and the recording interval was 5 minutes. The observational elements of mobile and fixed-point measurements include latitude and longitude of observation point, dry-bulb temperature, wet-bulb temperature, relative humidity, wind speed, air pressure, elevation height, dew point, wind heat index and wind chill index.

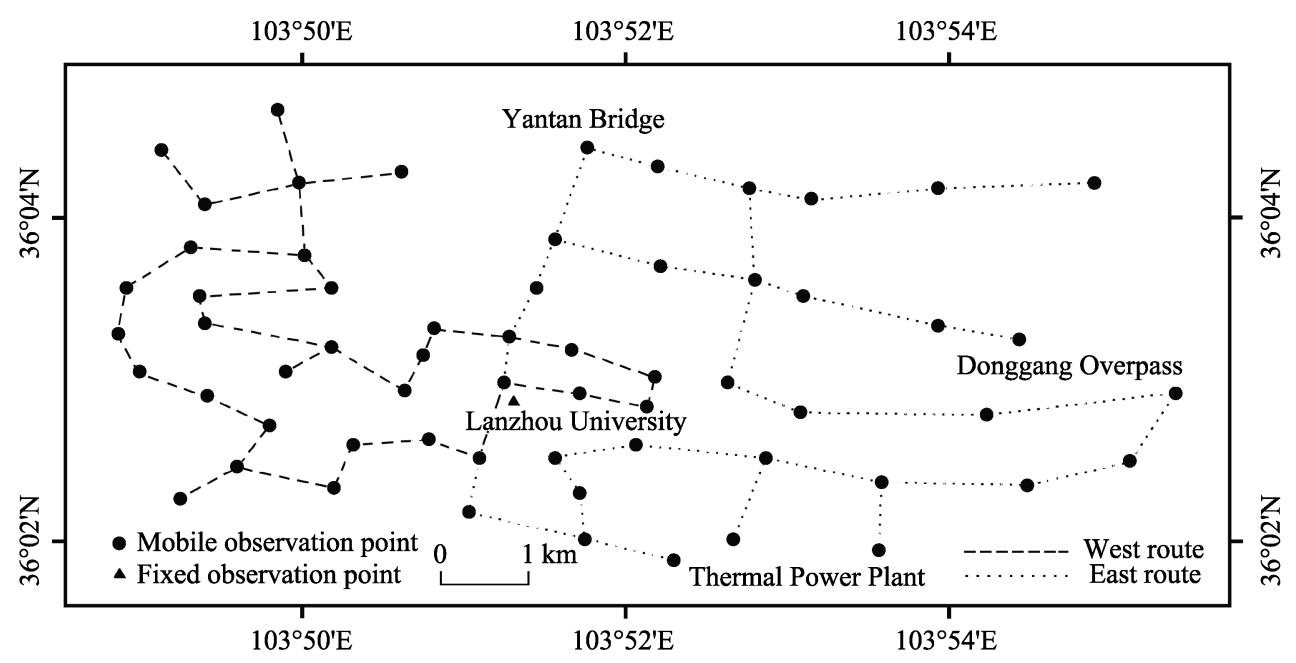

Figure 4 Measurement points and routes of mobile surveys of urban climate in typical urban area of Lanzhou

3.1.2 Comparative observation experiments of land-atmosphere heat fluxes and energy balance between urban and rural areas

Two Bowen-ratio Systems (SL5, Australia) were respectively installed in the Panxuan Road Campus of Lanzhou University in city center and the Yuzhong Campus of Lanzhou University in rural area (see Figure 5). Comparative observation experiments were continuously conducted for one year. Observational elements include the dry-bulb and wet-bulb temperature at the height of $0.5 \mathrm{~m}$ and $1.5 \mathrm{~m}$, net radiation, soil heat flux and wind speed. Recording interval was 10 minutes. Using the above observational elements, other meteorological elements can be thus calculated, including vapor pressure, relative humidity, dew point temperature, saturation vapor pressure, saturation deficit and specific humidity at the height of $0.5 \mathrm{~m}$ and $1.5 \mathrm{~m}$, sensible heat flux, latent heat flux and Bowen ratio value. All observation instruments were calibrated by the manufacturers. Air temperature sensors on the Bowen-ratio System and multi-functional meteorological instrument were calibrated by the platinum resistance thermometer, with a maximum permissible error of $\pm 0.1^{\circ} \mathrm{C}$. The humidity sensor was calibrated by the humidity generator with saturated aqueous salt solutions, with a maximum permissible error of $\pm 2 \%$. The net radiation sensor was calibrated by the reference net radiometer, its maximum permissible error was $\pm 5 \%$. The soil heat flux plates were calibration-free, and their measurement accuracy is within $\pm 5 \%$. 


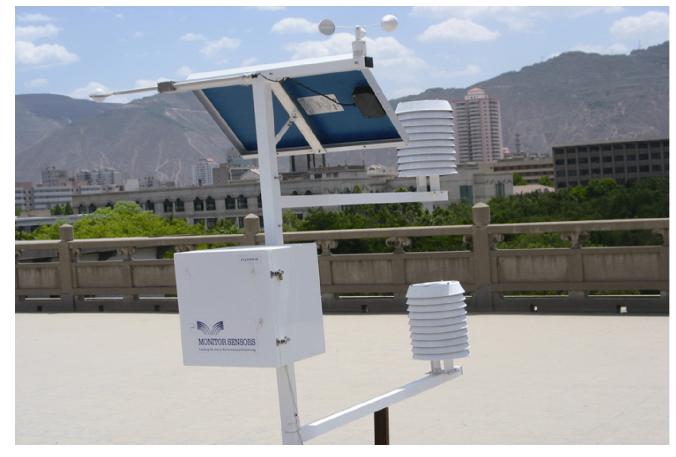

(a) Observation experiment in urban central area

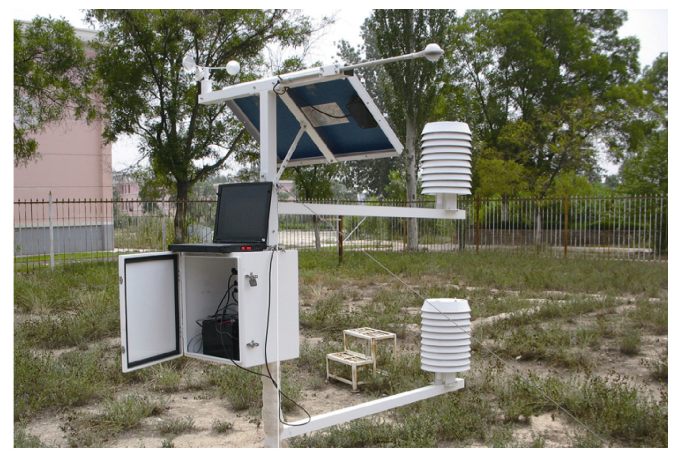

(b) Observation experiment in rural area

Figure 5 Comparative observation experiments between urban and rural areas using Bowen-Ratio Systems

\subsection{Remote sensing retrieval of urban LULC and NDVI}

In order to analyze the relationship between urban LULC, vegetation type with temperature and humidity fields, the LULC and NDVI are extracted from remote sensing images, Landsat-5 TM images that cover the whole study area were purchased from China Satellite Ground Station of Chinese Academy of Sciences. The date of images is September 18, 2007, which is close to the date of mobile observation experiments. The cloud cover of the upper left area of the images was $1 \%$ while it was zero for the rest of three districts. LULC of Lanzhou is classified according to the LULC classification procedures. The ISODATA algorithm of unsupervised classification method is used to carry on iteration clustering based on ENVI 5.3 software, combined with the current land-use map to confirm each classification attribute. LULC of Lanzhou is divided into 7 types in this study. NDVI is one of the best indicators to identify the type, growth status, and spatial distribution density of vegetation. Its value depends on the vegetation coverage and leaf area index. NDVI of Lanzhou is extracted through the geometric correction, radiometric calibration, atmospheric correction, and NDVI calculation procedures under ENVI 5.3 software environment.

\subsection{Datasets}

The daily meteorological data of Lanzhou central meteorological station in city center and Yuzhong County meteorological station in rural area during 1958-2019 were collected from Gansu Provincial Meteorological Bureau and China Meteorological Data Service Center (CMDC). The urbanization data and socioeconomic statistical data came from Lanzhou Statistical Yearbooks during past 70 years.

\subsection{Data process methods}

\subsubsection{Time difference correction of mobile observation data}

First, the fixed-point measurement data was used to correct the mobile measurement data at different time periods. Using the fixed-point measurement data taken every 5 minutes, the trend equation of measured values at every period was fitted by the least square method. Then, according to the trend equation, the relation between time and measured value of fixed-point measurement was used to correct the measured value of every measurement 
point of mobile measurement.

\subsubsection{Spatial database and spatial interpolation}

The spatial interpolation procedures are as follows: First, based on the corrected air temperature, relative humidity, and spatial location information at all mobile measurement points, the GIS spatial database was established using ArcGIS10.3 software. Second, the Geo-statistical module was used to perform a test on the spatial data so as to identify and adjust the distribution, outlier values, and overall trend of data. Third, a suitable interpolation was modeled to generate surface prediction. In this study, through statistical analysis and cross validation of the spatial data, the Inverse Distance Weight (IDW) method was selected to establish thermal and humidity fields. Finally, verifying the spatial interpolation results by cross validation method.

(1) Inverse Distance Weight

The IDW method takes the distance between interpolation point and sample point as the weight, so the weight contribution is inversely proportional to the distance. IDW has good effect in local variation simulation. It is defined as follows:

$$
Z\left(x_{0}\right)=\sum_{i=1}^{n} \frac{1}{\left(D_{i}\right)^{p}} Z_{i} / \sum_{i=1}^{n} \frac{1}{\left(D_{i}\right)^{p}}
$$

where $Z\left(x_{0}\right)$ is the predicted value of an unknown point $x_{0} ; Z_{i}$ is the observed value of the point $i ; D_{i}$ is the distance between the predicted and known observed points; and $p$ is the component of the distance.

(2) Cross validation

Cross validation method is used to verify the spatial interpolation results. The method assumed that the value of every observation point is unknown, it can be estimated by the observed values of the surrounding observation points. According to the error size between observed values and estimated values of all observation sites to judge whether the interpolation effect is good or bad. Mean Error (ME) and Root Mean Squared Error (RMSE) are selected as the evaluation criteria to estimate the error size of the spatial interpolation, which are demonstrated by the following equations:

$$
\begin{gathered}
M E=\frac{1}{n} \sum_{i=1}^{n}\left(\hat{z}_{i}-z_{i}\right) \\
R M S E=\sqrt{\frac{\sum_{i=1}^{n}\left(\hat{z}_{i}-z_{i}\right)^{2}}{n}}
\end{gathered}
$$

where $z_{i}$ is the realistic observed value of point $i ; \hat{z}_{i}$ is the estimated value; $n$ is the number of measured points.

\subsubsection{Data process of Bowen-ratio System experiments}

The observed elements of the Bowen-ratio System include the dry-bulb and wet-bulb temperatures at the height of $0.5 \mathrm{~m}$ and $1.5 \mathrm{~m}$, net radiation, soil heat flux, and wind speed. Using the above observational elements, other meteorological elements can be thus calculated, including vapor pressure, relative humidity, dew point temperature, saturation vapor pressure, saturation deficit and specific humidity at the height of $0.5 \mathrm{~m}$ and $1.5 \mathrm{~m}$. According to the gradient diffusion theory, the sensible heat flux, latent heat flux and Bowen ratio values 
over urban underlying surfaces can be calculated with the following equations:

$$
\begin{aligned}
L E & =\frac{R_{n}-G}{1+\beta}=\frac{R_{n}-G}{1+\gamma \frac{\Delta t}{\Delta e}} \\
\beta & =\frac{H}{L E} \\
R_{n} & =H+L E+G \\
\Delta t & =t_{0.5}-t_{1.5} \\
\Delta e & =e_{0.5}-e_{1.5}
\end{aligned}
$$

where $R_{n}$ is the net radiation; $H$ is the sensible heat flux; $L E$ is the latent heat flux, of which $L$ is the latent heat of vaporization $(2510 \mathrm{~J} / \mathrm{g})$ and $E$ is the evaporation rate or condensation rate. $G$ is soil heat flux; $\beta$ is the Bowen ratio value; $\Delta t$ is the air temperature difference between $0.5 \mathrm{~m}$ and $1.5 \mathrm{~m}$ height; $\Delta e$ is the vapor pressure difference between $0.5 \mathrm{~m}$ and $1.5 \mathrm{~m}$ height; and $\gamma$ is the psychrometer coefficient.

\section{Results and analysis}

\subsection{Dynamic characteristics of thermal and humidity fields in autumn}

\subsubsection{Dynamic characteristics of thermal field}

The spatial pattern of the thermal field at 8:30 on October 29, 2006 is demonstrated in
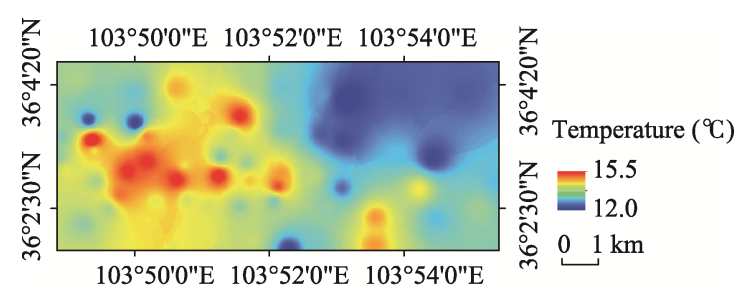

(a) Thermal field at $8: 30$

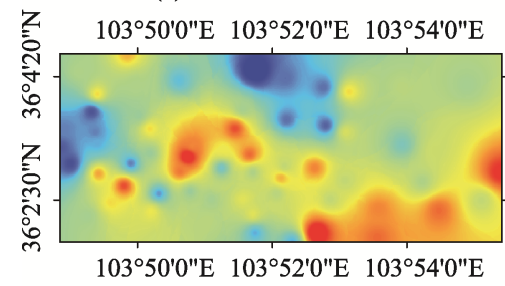

(b) Thermal field at $14: 30$
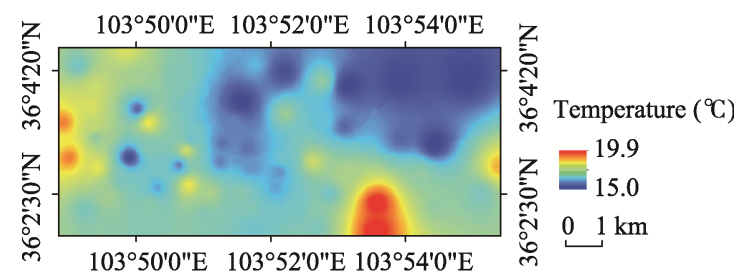

(c) Thermal field at 20:30

Figure 6 Diurnal variation of thermal field in autumn
Figure 6a. Urban thermal centers are located at the surrounding areas of Qingyang Road, Donggang West Road, Nanchang Road and Zhangye Road. The highest temperature appears at the provincial government area with a temperature of about $2{ }^{\circ} \mathrm{C}$ higher compared with the average of the whole area. The above-mentioned areas are mainly commerce and service industrial areas in Lanzhou; besides, due to the existence of multiple official administrative departments, the population density and the number of high-rise buildings are considerably higher. The areas with the lower temperature are identified to be in the east of the city except Dongzhan goods yard, which has some thermal patches. Thus, most of these areas, including Xingangcheng, Beimiantan village, Gaotan village and Junjiatan, have a relatively lower temperature. In general, the urbanization development level at 
these areas are relatively low, and their temperature is about $1^{\circ} \mathrm{C}$ below the average temperature of the whole area.

The spatial pattern of the ground thermal field at 14:30 on October 29, 2006 is demonstrated in Figure $6 \mathrm{~b}$. The thermal centers are mainly distributed in two areas. The larger one appears in the southeast of the city where located the second thermal power plant, Dongzhan goods yard, Gongxingdun and Donggang overpass, their temperature is about $1.6^{\circ} \mathrm{C}$ higher than the average temperature of the whole area. The vegetation coverage of the above-mentioned areas is relatively low, the area of the impervious surfaces is large, and the second thermal power plant and other factories also release lots of heat. The distribution of subordinate thermal centers is similar to that at 8:30, but its area is relatively smaller. The low temperature zones are concentrated in two areas; one is located at Yongchang Road, Shengli Hotel and around the Municipal Party Committee, and the other is situated in Yantan Bridge, Xingangcheng, and Hongyun Garden regions.

As illustrated in Figure 6c, the spatial ground temperature centers at 20:30 on October 29, 2006 are located at the edge of the urban areas where the recognizable one is located between Xiguan Cross and Yongchang Road with a temperature $2.1^{\circ} \mathrm{C}$ higher than the average temperature of the whole area. This area is known for its largest night market in Lanzhou and all kinds of business activities like the night fairs and food stalls are more distinctive during this time, thus it has attracts many people to get around. The second thermal center appears in the surrounding area of Dongzhan goods yard and Qingyang Hotel. This area is an obvious thermal center during three periods of whole day, which is closely related to its large area of warehouses and freight yard lands. Distribution of low temperature area is similar with that at 8:30, mainly in Yantan, due to its low development level and high vegetation coverage.

4.1.2 Dynamic characteristics of humidity field

The spatial patterns of humidity field at different periods on October 29, 2006 are demonstrated in Figure 7. The mean relative humidity of the whole area is $47.2 \%$ at 8:30, the areas with higher humidity such as Lanzhou Business College, Xidisuo, Donggang Overpass, The No.32 Middle School and Jiayuguan Road are mainly distributed in the east of the city. In addition, the Yellow River bridge park vicinity is a high humidity area. The surrounding areas of Panxuan Road and Huanghe (Yellow River) Hospital have a lower humidity value. Humidity field at 14:30 does not show a strong regularity,

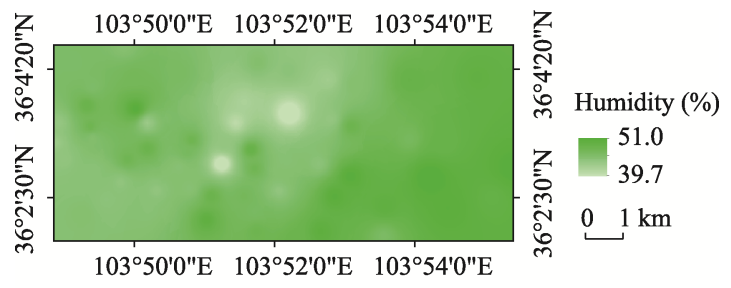

(a) Humidity field at $8: 30$

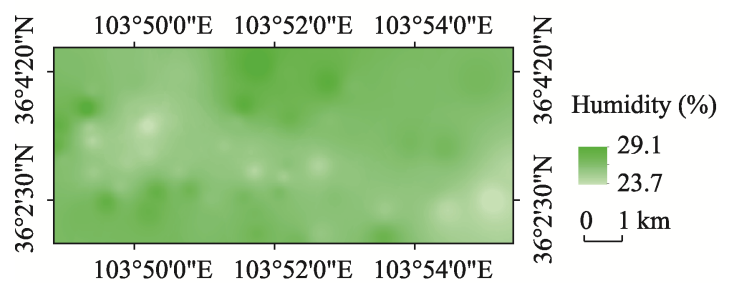

(b) Humidity field at $14: 30$

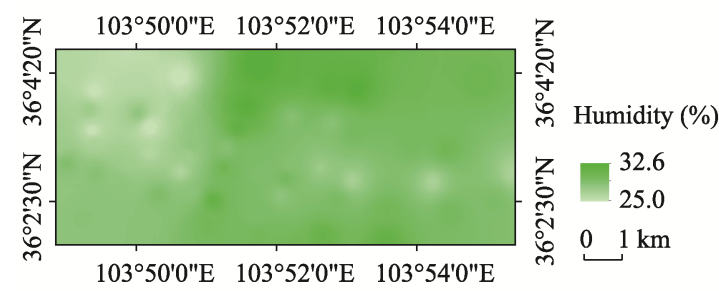

(c) Humidity field at 20:30

Figure 7 Diurnal variation of humidity field in autumn 
the mean relative humidity of the whole area is $26.3 \%$, and the regional difference is also small. The mean relative humidity of the whole area is $28.8 \%$ at $20: 30$ where north of Yantan bridge, Jiantanzi and Beimiantan villages are within high humidity areas. The foothill of South Mountain is the second high humidity area. The area encircled by Guangwumeng, provincial government, Nanguan Cross and the western entrance of square has lower relative humidity. The above-mentioned areas are important political, financial and commercial centers of the city, and have a high density of population and buildings.

In general, the mean relative humidity of the whole area at 8:30, 14:30 and 20:30 are $47.2 \%, 26.3 \%$ and $28.8 \%$, respectively. The humidity field is strong in the morning, and it is consistent with the typical change of the relative humidity within a day, which depends on the temperature change. With the temperature rising, the evaporation and vapor pressure are also increasing. But the saturated vapor pressure increases more than vapor pressure, so the relative humidity is decreasing. When the temperature is decreasing, the result is opposite. Considering of spatial pattern of the humidity field, there are huge overlaps between the high humidity areas and vegetation coverage areas, like Gaotan, Wuquan Park are all high humidity value areas.

The humidity value of the city center is low in general such as the surrounding area of Donggang Road, which is very obvious around the second thermal power plant. For the densely populated areas, business districts and concentrated buildings area, according to the previous analysis of the thermal field intensity, their temperature is generally higher. Thus, the saturation vapor pressure of these areas is totally at a high level, which eventually forces the relative humidity to a low level. Therefore, the high or low relative humidity value is bound up with the thermal field intensity. Besides, due to the influence of the Yellow River, the relative humidity of the nearby areas is generally at a high level.

4.1.3 Simulation accuracy verification of temperature and humidity fields

Cross validation method is used to verify the spatial interpolation results of temperature and humidity fields. The results of the cross validation are presented in Table 1. ME reflects the error range of the estimated values; the closer ME to zero, the better estimation effect. Also, RMSE reflects the estimation sensitivity and extreme effect, the smaller RMSE value means the better estimation effect. The simulation precision of thermal and humidity fields is generally high in this study.

Table 1 Results of the cross validation

\begin{tabular}{|c|c|c|c|c|c|c|}
\hline & $\begin{array}{l}\text { Temperature } \\
\text { at 8:30 }\left({ }^{\circ} \mathrm{C}\right)\end{array}$ & $\begin{array}{l}\text { Temperature } \\
\text { at } 14: 30\left({ }^{\circ} \mathrm{C}\right)\end{array}$ & $\begin{array}{l}\text { Temperature } \\
\text { at } 20: 30\left({ }^{\circ} \mathrm{C}\right)\end{array}$ & $\begin{array}{c}\text { Relative humidity } \\
\text { at } 8: 30(\%)\end{array}$ & $\begin{array}{l}\text { Relative humidity } \\
\text { at } 14: 30(\%)\end{array}$ & $\begin{array}{l}\text { Relative humidity } \\
\text { at } 20: 30(\%)\end{array}$ \\
\hline Mean Error (ME) & 0.07 & 0.04 & -0.02 & -0.03 & -0.13 & -0.10 \\
\hline $\begin{array}{l}\text { Root Mean } \\
\text { Squared Error } \\
\text { (RMSE) }\end{array}$ & 0.70 & 0.94 & 0.88 & 1.98 & 1.03 & 1.25 \\
\hline
\end{tabular}

\subsection{Spatial patterns of LULC and green space}

In order to analyze the relation between the LULC, vegetation type with the temperature and humidity fields, the LULC and NDVI are extracted from remote sensing images. Landsat-5 TM images cover the whole study regions, it is close to the date of mobile measurement ex- 
periments. LULC of Lanzhou is classified according to the land use status classification procedures. The national land-use classification system has two levels: level one has 8 types, and level two has 46 types. The ISODATA algorithm of unsupervised classification method is used to carry on iteration clustering, it then combined with the present land-use map to confirm each classification attribute. LULC of Lanzhou is divided into 7 types in this study, they are urban construction land, water area, forest land, grassland, agricultural land, industrial land and other types as shown in Figure 8.

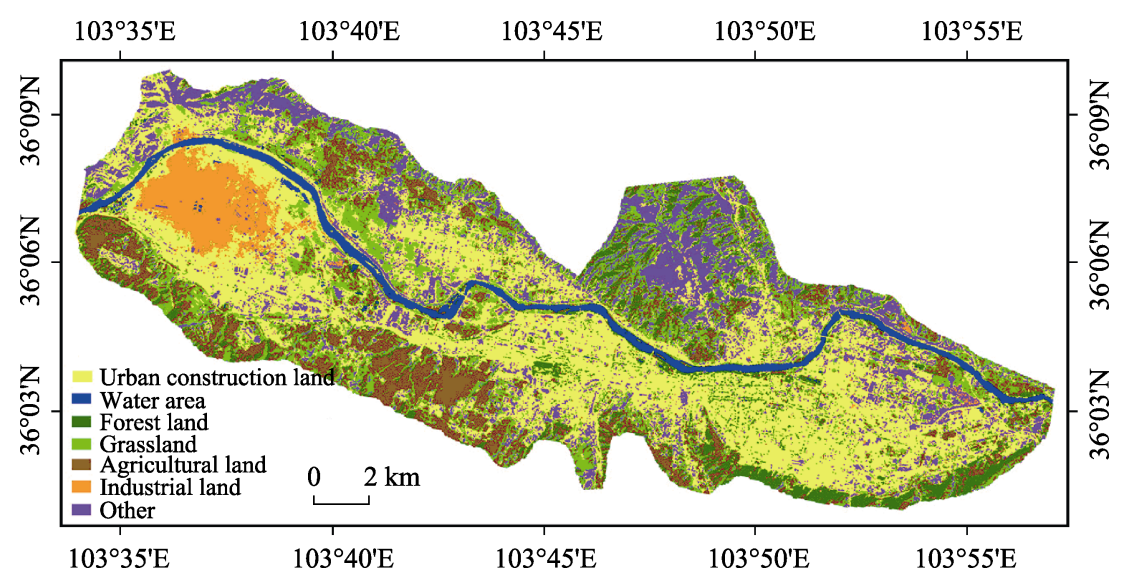

Figure 8 Lanzhou land use/land cover map

There is a close relationship between the structural characteristics of the temperature and humidity fields and the spatial distribution of urban impervious surfaces. The distributions of the thermal and humidity fields in Lanzhou have multiple centers and intensity level characteristics. The thermal centers are mainly distributed in the high density regions in terms of population and buildings, in the regions with high emission of anthropogenic heats, in the heavy traffic zones, and in the industrial districts. On the contrary, there are obvious high-value areas in the humidity field and low-value areas in the thermal field located in watery areas, vegetated regions, and the places with a low intensity of human activities.

NDVI is one of the best indicators to identify the growth status and spatial distribution density of vegetation (Yuan et al., 2019). There are linear correlations between NDVI and the spatial distribution density of plants. NDVI is the comprehensive reflection of vegetation type, covering form and growth status, which is sensitive to the change of the soil background. Its value depends on the vegetation coverage and leaf area index. NDVI has good adaptability for both time and space. In order to know the spatial distribution and structural characteristics of vegetation in Lanzhou, NDVI of Lanzhou is extracted through the geometric accurate correction, radiometric calibration, atmospheric correction, and NDVI calculation procedures. The NDVI spatial pattern of Lanzhou is as shown in Figure 9.

The value range of NDVI is between -1 and 1 , a higher value indicates a more green vegetation. A pixel is totally covered by the bare soil or building when $\mathrm{NDVI}<0.2$, by the vegetation when $\mathrm{NDVI}>0.5$, and by a combination of the bare surface and vegetation when $0.2 \leqslant \mathrm{NDVI} \leqslant 0.5$ (Sobrino et al., 2004). Analyzing the relationship between the NDVI distribution and temperature/humidity fields in Lanzhou reveals that the most areas with NDVI $<0.1$ are urban impervious surfaces, which are usually covered by buildings. These areas 
thus show features of high thermal and low humidity field intensities. The high vegetation coverage areas with NDVI $>0.5$, such as Xujiashan forest park, Wuquan park, Gaotan village, Anning peach orchard, Yuanmao mountain, correspond with high humidity and low temperature regions. On the whole, there are negative correlations between the NDVI value and thermal field intensity and positive correlations between the NDVI value and humidity field intensity. Therefore, it can be concluded that the higher vegetation coverage is, the lower surface temperature, and the higher relative humidity.

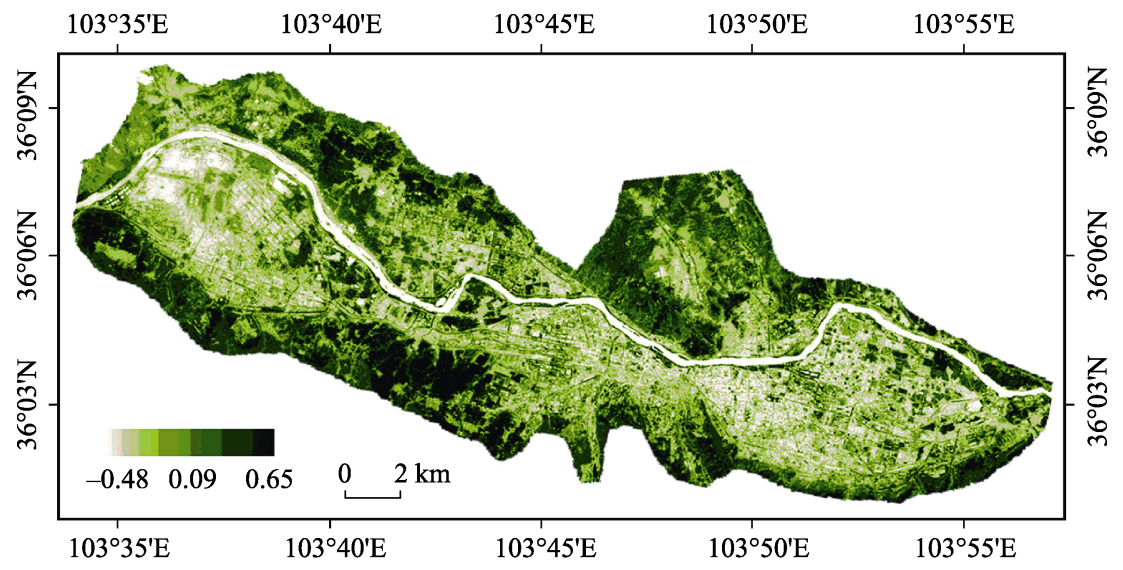

Figure 9 NDVI spatial pattern of Lanzhou

\subsection{Heat fluxes and energy balance between underlying surface and atmosphere}

Urban morphology is complex and heterogeneous, which strongly influences on the wind field, temperature field, and turbulent field as well as the surface energy balance, distribution of water vapour and matter. In this study, using observation data of the Bowen ratio System to solve equations (4), (5), (6), (7) and (8), the latent heat flux, sensible heat flux and Bowen ratio value can be calculated. Therefore, the daily variation of the net radiation, sensible heat flux, latent heat flux and soil heat flux in autumn is shown as Figure 10.

Analyzing land-atmospheric heat fluxes and energy balance characteristics during the mobile measurement, amplitude of the diurnal variation curve of the net radiation gradually decreases. The maximum value of the net radiation density also gradually decreases in accordance with the inclination of the sun elevation angle. Its maximum value regularly appears around 13:30, which is associated with the highest surface temperature, causing the radiation difference curve to be in an asymmetric form in the noon. The time in which the net radiation converts from a negative value to a positive one is gradually postponed and generally occurs at $1.5 \mathrm{~h}$ after the sunrise. Inversely, the time in which the net radiation converts from a positive value to a negative one is gradually advanced and mostly occurs at $1-1.5 \mathrm{~h}$ before the sunset. The main reason is associated to the time after sunrise that helps to absorb the shortwave radiation. When this value starts to exceed the effective radiation, the effective radiation exceeds the shortwave absorption radiation just begins at some time before sunset at dusk. The daily cumulation of the radiation balance gradually decreases month by month, indicating that the surface energy loss becomes also higher. Positive radiation balance during the daytime is about four times of the negative radiation 
balance during the night.

As shown in Figure 10b, the net radiation, latent heat flux and sensible heat flux convert from a negative value to a positive one at about 8:00. Since then, the net radiation rapidly increases, simultaneously, every component of the heat fluxes quickly and also gradually increases. The net radiation reaches to the maximum value with 496.9 $\mathrm{W} / \mathrm{m}^{2}$ at about 13:50; during this period, a short jump in the net radiation and sensible heat fluxes happens at 13:00. This is due to the existence of clouds and blockage of the radiation at that time. The latent heat flux reaches its maximum value with 302.5 $\mathrm{W} / \mathrm{m}^{2}$ at about 13:50 while the sensible heat flux reaches its maximum value with 92 $\mathrm{W} / \mathrm{m}^{2}$ at 14:00. The soil heat flux also converts from a negative value to a positive one at about 12:00, which means that the underlying surface heat starts to be transferred from the surface to the soil. $74 \%$ and $26 \%$ of the net radiation convert into the latent heat and sensible heat, respectively. During the afternoon with the weaker solar radiation and turbulent exchange, the atmospheric stratification is gradually stabilized, and every flux component is gradually decreased. At about 17:30, the net radiation converts from a positive value to a negative one. Hereafter, the ground long-wave radiation is more than the downward atmospheric long-wave radiation, ground surface remains heat loss throughout the night. The

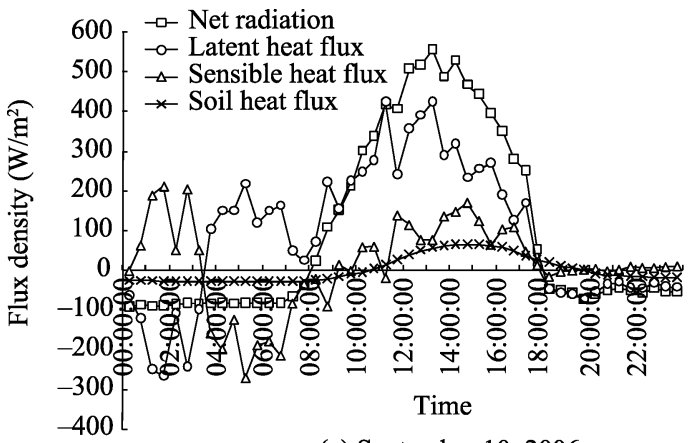

(a) September 10, 2006

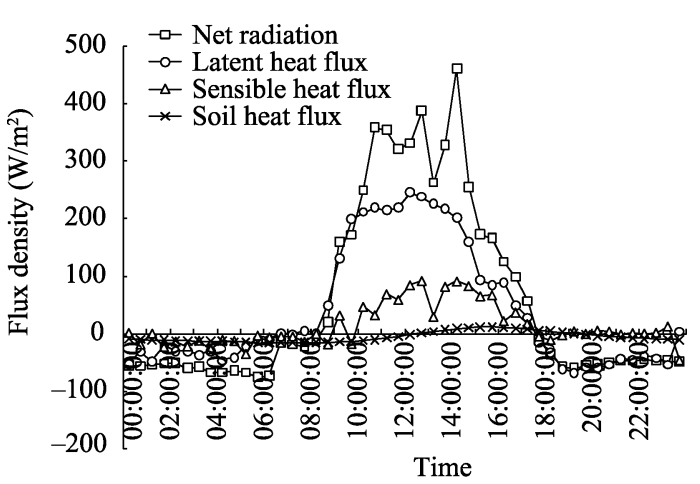

(b) October 6, 2006

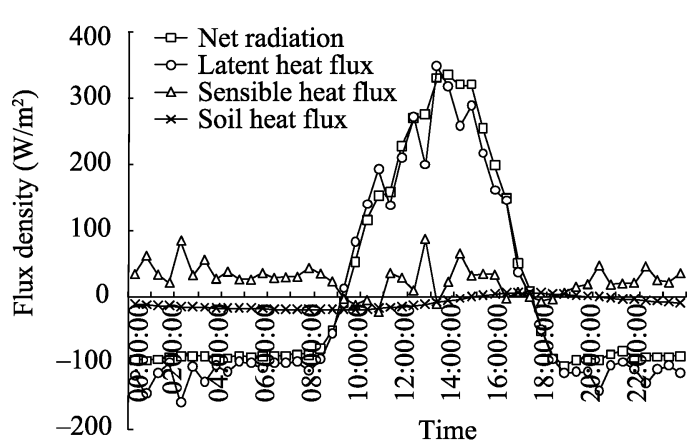

(c) November 11, 2006

Figure 10 Land-atmosphere heat fluxes and energy balance in autumn net radiation shows a small fluctuation for the whole night with a minimum value of -74.8 $\mathrm{W} / \mathrm{m}^{2}$ at about $5: 30$. The soil heat flux begins to be transferred from the depth to the surface at about 19:30, so that the temperature of the underlying surface is not too low during the night.

The land with a higher vegetation coverage usually has a larger thermal inertia and capacity and a lower heat conduction and radiation. The heat storage volume of the concrete pavement and building surfaces are equivalent to $15 \%-30 \%$ of the net radiation. Moreover, the heat storage volume of the forest and grass grounds is only $5 \%-15 \%$ of the net radiation. As the sensible heat flux and Bowen ratio values of the urban artificial building land are higher than that of high-vegetation coverage area, the heat transfer from the underlying sur- 
face to atmosphere increases. Thus, urban artificial building land has a significant impact on the temperature field and heat island intensity. In addition, with the increase of urban impervious surface, the water capacity of ground rapidly decreases, the heating effect of latent heat flux weakens more gradually than that of sensible heat flux, the Bowen ratio value will increase with the growth of impervious surface area.

\section{Discussion}

The LULC type is the key factor for linking the thermal field, humidity field, and energy budget. The distribution patterns of the thermal and humidity fields have close relationships with LULC. There is a significant positive correlation between impervious surface area and thermal field intensity; thermal centers are mainly located in commercial areas, industrial districts, transportation junctions and other urban impervious surfaces; high humidity and low temperature areas are located in watery areas, areas with high vegetation coverage, and places with a low intensity of human activities. Concrete ground and lawns are the two most representative types of LULC, there are obvious differences in the characteristics of thermal and humidity fields, so the comparative observation experiments of energy budget were conducted on these two surfaces.

The results of cross validation show that the simulation precision of thermal and humidity fields is generally high based on the mobile observation, fixed-point observation and GIS spatial analysis methods. Qin and Kamieli (2002) evaluated the inversion error of thermal infrared remote sensing, and found that the inversion error of the ground temperature is more than $1.2^{\circ} \mathrm{C}$ based on the Mono-window algorithm, the inversion error is more than $1.5^{\circ} \mathrm{C}$ based on the generalized single-channel algorithm. In addition, compared with the other research results of Lanzhou (Pan and Han, 2011; Li et al., 2016), this study has better precision as well.

Results indicate that the distributions of the thermal and humidity fields in Lanzhou have multiple centers and intensity level characteristics. With the rapid urbanization, urban construction land has expanded quickly. There is a close relationship between the structural characteristics of the thermal and humidity fields and the spatial distribution of urban impervious surface. Jato-Espino (2019) also found the urban impervious surface has the biggest area in urban heterogeneous surfaces, its albedo coefficient and thermodynamic properties are significantly different from the natural underlying surface, and therefore has obvious influence on the thermal and dynamic structures of the urban boundary layer. Compared with the other research results of river valley cities in western China such as Urumqi and Chongqing, Maimaitijiang and Alimujiang (2015) also found the abundance of impervious surface area is positively correlated with LST, and vegetation fraction is negatively correlated with LST in Urumqi city's built-up area; bare soil has high LST, and has significant influence on the formation of heat island and the surface thermal environment. Jin et al. (2018) demonstrated vegetation coverage, building height, roofs types, arrangement position and regional layouts influenced regional thermal environment in Chongqing, with the same vegetation coverage, the effectiveness of air temperature dropping of the whole region differed according to the arrangement position.

As mentioned previously, there are negative correlations between the NDVI value and 
thermal field intensity and positive correlations between the NDVI value and humidity field intensity. Therefore, it can be concluded that the higher vegetation coverage is, the lower the surface temperature, and the higher the relative humidity. With increasing of the artificial constructions in the city, vegetation is reduced, and the impervious surface area is increased. So, the water storage capacity is weakened, and as a result, humidity of the urban underlying surface becomes smaller. This implies that the reduction in the vegetation coverage and urban humidity causes the urban temperature to increase. Consistent with this study, relevant researches have shown that when the natural vegetation cover transforms into urban construction land type, a larger temperature variation is expected (Cao et al., 2013; Gao et al., 2019). Peng et al. (2009) found that every $10 \%$ reduction in the vegetation coverage results in an increase of $0.49^{\circ} \mathrm{C}$ in the land surface air temperature in mountainous city; Wang and Shu (2020) argued that UHI mitigation strategies should increase vegetation coverage, as a $10-20 \%$ increase in vegetation coverage is anticipated to reduce the UHI by $0.38-0.78^{\circ} \mathrm{C}$. Zhu et al. (2011) suggested that urban greening has cooling and humidification effects when the greenbelt width is more than $42 \mathrm{~m}$. Hence, a reasonable planning of the green area is very important in the construction process of an ecological city.

The urban impervious surface has a higher sensible heat flux and a lower latent heat flux, thus, its Bowen ratio value is high. On the contrary, there are a lower sensible heat flux and a higher latent heat flux in green space and water, and their Bowen ratio values are lower. The sensible heat flux and Bowen ratio values of the urban artificial building land are higher than that of high-vegetation coverage area, the heat transfer from the underlying surface to atmosphere increases. Thus, urban artificial building land has a significant impact on the thermal field and heat island intensity. The findings were in line with the prior studies, Kuang et al. $(2015,2017,2020)$ systematically studied the thermal environment, surface radiation, and heat fluxes in Beijing, indicated that difference of thermal environments among urban functional areas is closely related to the proportions of the land-cover components, and found that the LST, sensible heat flux and Bowen ratio value increased along the outskirt-suburban-urban gradient, the net radiation flux and turbulent heat flux exhibit strong spatial heterogeneity. Mariani et al. (2016) also indicated that different underlying surfaces have different impacts on the surface energy balance; Liu et al. (2012) found that the Bowen ratio value of different underlying surface types can be ranked as industrial land, residential land, traffic land, public facilities land, dry land, public green space, and water area. Hence, reasonable land use planning and urban planning are critical for urban eco-environment construction of valley cities.

\section{Conclusions}

Taking Lanzhou as a case of typical valley-city to monitor urban climate characteristics and their energy driving mechanism, mobile measurement, fixed-point measurement and GIS spatial analysis methods are used to simulate the spatial structure and dynamic evolution of temperature and humidity fields. LULC and NDVI are extracted from remote sensing images, the spatial structure relations between temperature field, humidity field, LULC and NDVI are analyzed. The land-atmospheric heat fluxes and energy balance are analyzed to explain the energy driving mechanism based on the Bowen-ratio System comparative ex- 
periments.

(1) Temperature and humidity fields have significant dynamic change within a day in autumn, and have multiple centers and multiple intensity levels characteristics. Urban thermal centers at 8:30 are located at the commerce and service industrial areas. The thermal centers at 14:30 are mainly distributed in the thermal power plant, and goods yard areas. The obvious thermal centers at 20:30 are located at the largest night market in Lanzhou, and all kinds of business activities like the night fairs and food stalls are more attractive during this time period. Low temperature areas are mainly distributed at the Yellow River beach with low development level and high vegetation coverage.

(2) The high humidity areas at 8:30 are mainly distributed in the east of the city, the humidity field is strong in the morning. Humidity patterns at 14:30 show dispersive distribution, and spatial difference of humidity is small. High humidity areas at 20:30 are mainly distributed at the Yellow River beach and the foothills of South Mountain. Low humidity areas are located at political, financial and commercial centers with high density of population and buildings. High humidity area and high vegetation coverage area are overlapped, and the size of relative humidity value is bound up with the thermal field intensity.

(3) The daily variations of the net radiation, sensible heat flux, latent heat flux and soil heat flux over urban heterogeneous surfaces are obvious, which drive the variations of temperature and humidity fields. Positive radiation budget during the daytime is about four times of negative radiation budget during the night. The building land has a higher sensible heat flux, a lower latent heat flux and a higher Bowen ratio value. Green space and waters have lower sensible heat flux, higher latent heat flux and lower Bowen ratio value. Sensible heat flux and Bowen ratio value of urban impervious surfaces are higher than that of high vegetation coverage area, it has a significant impact on the thermal field and the UHI intensity.

(4) The distribution patterns of temperature and humidity fields have close relationships with LULC and NDVI. There is a significant positive correlation between impervious surface area and thermal field intensity, thermal centers are mainly located in commercial areas, industrial districts and transportation junctions; high humidity and low temperature areas are located in watery areas, vegetated regions, and the places with a low intensity of human activities. A positive correlation between NDVI value and humidity field intensity has been found as well as a negative correlation between NDVI value and thermal field intensity.

\section{References}

Akbari H, Kolokotsa D, 2016. Three decades of urban heat islands and mitigation technologies research. Energy and Buildings, 133: 834-842.

Arnds D, Böhner J, Bechtel B, 2017. Spatio-temporal variance and meteorological drivers of the urban heat island in a European city. Theoretical and Applied Climatology, 128(1): 43-61.

Benas N, Chrysoulakis N, Cartalis C, 2017. Trends of urban surface temperature and heat island characteristics in the Mediterranean. Theoretical and Applied Climatology, 130(3): 807-816.

Cao W, Shao Q Q, Liu J Y et al., 2013. Impact of land use/land cover and its change on climate warming in Beijing area. Climatic and Environmental Research, 18(4): 451-460. (in Chinese) 
David E, 2004. Large-scale warming is not urban. Nature, 432(7015): 290.

Gao J, Jiao K, Wu S, 2019. Investigating the spatially heterogeneous relationships between climate factors and NDVI in China during 1982 to 2013. Journal of Geographical Sciences, 29(10): 1597-1609.

Grimm N B, Faeth S H, Golubiewski N E et al., 2008. Global change and the ecology of cities. Science, 319(5864): 756-760.

Ho H C, Knudby A, Xu Y M et al., 2016. Comparison of urban heat islands mapped using skin temperature, air temperature, and apparent temperature (humidex), for the greater Vancouver area. Science of the Total Environment, 544: 929-938.

Jato-Espino D, 2019. Spatiotemporal statistical analysis of the Urban Heat Island effect in a Mediterranean region. Sustainable Cities and Society, 46: 101427.

Jin C, Bai X, Luo T et al., 2018. Effects of green roofs' variations on the regional thermal environment using measurements and simulations in Chongqing, China. Urban Forestry \& Urban Greening, 29: 223-237.

Kalnay E, Cai M, 2003. Impact of urbanization and land-use change on climate. Nature, 423(6939): 528-531.

Kourtidis K, Georgoulias A K, Rapsomanikis S et al., 2015. A study of the hourly variability of the urban heat island effect in the Greater Athens Area during summer. Science of the Total Environment, 517: 162-177.

Kuang W, Dou Y, Zhang C et al., 2015. Quantifying the heat flux regulation of metropolitan land use/land cover components by coupling remote sensing modeling with in situ measurement. Journal of Geophysical Research: Atmospheres, 120(1): 113-130.

Kuang W, Yang T, Liu A et al., 2017. An EcoCity model for regulating urban land cover structure and thermal environment: Taking Beijing as an example. Science China Earth Sciences, 60(6): 1098-1109.

Kuang W, Li Z, Hamdi R, 2020. Comparison of surface radiation and turbulent heat fluxes in Olympic Forest Park and on a building roof in Beijing, China. Urban Climate, 31: 100562.

Li G D, Zhang X, Mirzaei P A et al., 2018. Urban heat island effect of a typical valley city in China: Responds to the global warming and rapid urbanization. Sustainable Cities and Society, 38: 736-745.

Li X, Yang X Q, Tang J P et al., 2011. Multiple urban heat islands and surface energy balance during summer in Yangtze River Delta city cluster region simulated with WRF/NCAR. Journal of the Meteorological Sciences, 31(4): 441-450. (in Chinese)

Li X Q, Lu Z, Li Y S, 2016. Study on the characteristics and driving mechanism of the heat island effect in Lanzhou. Journal of Lanzhou University (Natural Sciences), 52(1): 69-74. (in Chinese)

Liu Y, Shintaro G, Zhuang D F et al., 2012. Urban surface heat flux inversion based on infrared remote sensing and the relationship with land cover. Acta Geographica Sinica, 67(1): 101-112. (in Chinese)

Maimaitijiang M, Alimujiang K, 2015. Study on land surface characteristics and its relationship with land surface thermal environment of typical city in arid region. Ecology and Environmental Sciences, 24(11): 1865-1871. (in Chinese)

Mariani L, Parisi S G, Cola G et al., 2016. Climatological analysis of the mitigating effect of vegetation on the urban heat island of Milan, Italy. Science of the Total Environment, 569: 762-773.

Melaas K E, Wang A J, Miller L D et al., 2016. Interactions between urban vegetation and surface urban heat islands: A case study in the Boston metropolitan region. Environmental Research Letters, 11(5): 054020.

Mirzaei P A, Haghighat F, 2010. Approaches to study urban heat island: Bilities and limitations. Building and Environment, 45(10): 2192-2201.

Pan J H, Han W, 2011. Urban expansion and its heat island response in Lanzhou city based on remote sensing analysis. Chinese Journal of Ecology, 30(11): 2597-2603. (in Chinese)

Peng Z, Liao H P, Guo Y T, 2009. Influence of land cover change on land surface temperature in the mountainous city. Geographical Research, 28(3): 673-684. (in Chinese)

Qi J, Ding L, Lim S, 2020. Ontology-based knowledge representation of urban heat island mitigation strategies. Sustainable Cities and Society, 52: 101875. 
Qin Z, Kamieli A, 2002. A mono-window algorithm for retrieving land surface temperature from Landsat TM data and its application to the Israel-Egypt border region. International Journal of Remote Sensing, 22(18): 3719-3746.

Rajasekar U, Weng Q H, 2009. Spatio-temporal modelling and analysis of urban heat islands by using Landsat TM and ETM plus imagery. International Journal of Remote Sensing, 30(13): 3531-3548.

Rizwan A M, Dennis L Y C, Liu C H, 2008. A review on the generation, determination and mitigation of urban heat island. Journal of Environment Sciences, 20(1): 120-128.

Schatz J, Kucharik J C, 2015. Urban climate effects on extreme temperatures in Madison, Wisconsin, USA. Environmental Research Letters, 10(9): 094024.

Shao Q, Sun C Y, Liu J Y et al., 2009. Impact of urban expansion on meteorological observation data and overestimation to regional air temperature in China. Acta Geographica Sinica, 64(11): 1292-1231. (in Chinese)

Shirani-Bidabadi N, Nasrabadi T, Faryadi S et al., 2019. Evaluating the spatial distribution and the intensity of urban heat island using remote sensing, case study of Isfahan city in Iran. Sustainable Cities and Society, 45: 686-692.

Silva J S, Silva R M D, Santos C A G, 2018. Spatiotemporal impact of land use/land cover changes on urban heat islands: A case study of Paco do Lumiar, Brazil. Building and Environment, 136: 279-292.

Small C, 2006. Comparative analysis of urban reflectance and surface temperature. Remote Sensing of Environment, 104(2): 168-189.

Sobrino J A, Jimenez-Munoz J C, Paolini L, 2004. Land surface temperature retrieval from Landsat TM5. Remote Sensing of Environment, 90(4): 434-446.

Wang S W, 2010. Debating about the global warming. Chinese Science Bulletin, 55(16): 1529-1530. (in Chinese)

Wang W, Shu J, 2020. Urban renewal can mitigate urban heat islands. Geophysical Research Letters, 47(6): 085948 .

Yang S P, Lv S H, Chen Y C, 2010. Simulation of afforestation effect on urban boundary layer structure of valley city in winter. Journal of Desert Research, 30(3): 691-698. (in Chinese)

Yuan L, Chen X, Wang X et al., 2019. Spatial associations between NDVI and environmental factors in the Heihe River Basin. Journal of Geographical Sciences, 29(9): 1548-1564.

Zhang R H, Tian J, Li Z L et al., 2010. Principles and methods for the validation of quantitative remote sensing products. Science China: Earth Science, 40(2): 211-222. (in Chinese)

Zhu C, Li S, Ji P et al., 2011. Effects of the different width of urban green belts on the temperature and humidity. Acta Ecologica Sinica, 31(2): 383-394. (in Chinese)

Zipper S C, Schatz J, Singh A et al., 2016. Urban heat island impacts on plant phenology: Intra-urban variability and response to land cover. Environmental Research Letters, 11(5): 054023. 